\title{
Carnal Hermeneutics and the Digital Game
}

\author{
Paul Martin
}

Carnal hermeneutics claims that the body makes sense of the world by making distinctions and evaluating those distinctions in a non-predicative mode. This article makes the case that ludohermeneutics can be enriched by attending to the way in which the body makes sense of digital games and advances carnal hermeneutics as a way of theorising this process. The article introduces carnal hermeneutics, argues for its relevance to ludo-hermeneutics, and outlines three examples of how carnal hermeneutics can be used to theorise sense-making in digital games. The first example demonstrates the capacity for touch-screen games to put us in a new relationship with the image. The second example shows how generic control schemas can take on new meanings in different games. The third example shows how marketing of game controllers draws on conventional attitudes to touch to make digital game touch meaningful.

Keywords: carnal hermeneutics, interpretation, Merleau-Ponty, embodiment, close reading, phenomenology

\section{Introduction}

From the moment a computer game player picks up the controller, grasps the mobile phone or lays their hands on the keyboard they are already making sense of the digital game. This sense-making occurs across a range of modalities. In making sense of the game we draw on our memory of other games we've played and other technology we've interacted with. We make hypotheses about the game's meaning based on its title, its publisher, and the opening screens. We decode the story and the artwork with skills learned formally and informally in a range of other contexts: classrooms and theatres; libraries and cinemas; arcades and internet cafés. We derive meanings from the combination of characters, themes and stories, as well as mechanics, difficulty curves and control mechanisms.

This article addresses the role of the body in this rich ecology of interpretation. While the body has been an important topic in game studies, and the relationship between the body and interpretation has been discussed in other media forms, what is missing is the development of theory that addresses the link between the body and in- 
terpretation in games. In the argument that follows, I wish to demonstrate that the body is fundamental to the process of interpretation in games. If this is true, then the relationship between the body and interpretation-what I am referring to here, drawing on Kearney (2015), as “carnal hermeneutics”-must be considered in any theory of meaning-making in games. More specifically, the article argues that we make sense of games through sensation in a non-predicative, pre-linguistic mode whereby we evaluate distinctions. We then make use of these evaluations in any predicative assertions we make about what a game means. The following section summarises literature on the crossroads of games and hermeneutics, locating the present article in the area of ludohermeneutics. The following two sections introduce "carnal hermeneutics" and argue for its relevance in games. This is followed by three examples of how carnal hermeneutics might be applied to game studies. These sections involve close readings of a touchscreen mobile game, an indie PC game, and recent marketing copy for console controllers. The article concludes with some recommendations for how carnal hermeneutics might be developed in relation to the study of digital games.

\section{Classical Hermeneutics, Philosophical Hermeneutics and Ludo-Hermeneutics}

Veli-Matti Karhulahti (2015) identifies two different ways of approaching hermeneutics in digital game theory and criticism. The first is derived from the classical hermeneutic tradition exemplified by Schleiermacher and other aestheticians of the $18^{\text {th }}$ and $19^{\text {th }}$ centuries; the second from the $20^{\text {th }}$ century philosophical hermeneutics of, most notably, Heidegger and Gadamer. The main theoretical question in classical hermeneutics is how people make sense of, primarily, written and spoken texts. The practical questions that follow from this are to do with how people-particularly professional critics and translators - ought to make sense of these texts. Philosophical hermeneutics is also concerned with understanding, but casts its net wider. It is interested in understanding as such: how people understand the world, each other and themselves. Karhulahti shows that when game scholars discuss hermeneutics some adopt a classical, others a philosophical approach. The former approach the digital game as a "text artefact"; the latter approach "videogaming as a phenomenological process" (Karhulahti 2015, 3).

Some game scholars advance a hermeneutics that draws on both of these traditions. Espen Aarseth (Aarseth 2003) describes "real-time hermeneutics" as an iterative and reflective form of sense-making in digital games (see also Arjoranta 2011). In his methodological article on game analysis, he advances this as both a theoretical account of how players in fact make sense of games and a practical approach to conducting academic analyses. In real-time hermeneutics the player takes into account his or her own performance in making conclusions about what a game means. This is a combination of classical and philosophical hermeneutics in the sense that the player is feeding a particular understanding of the phenomenological process of gameplay (philosophical herme- 
neutics) into a more standard "reading” of the game's theme (classical hermeneutics). This became a fairly common approach to game criticism (both academic and journalistic) in the mid to late 2000s, for example in essays on Bioshock that recuperated the player's direct experience of submitting to authority as a requirement of gameplay to deepen a more standard reading of the game's backstory or theme of authoritarianism and freedom (for a summary see Clarkson 2009). Elsewhere, Aarseth (2013) briefly describes a similar focus on the relationship between gameplay and meaning as "ludohermeneutics.” This approach, drawn from Gadamer's (2004) description of understanding as a form of play, emphasises "the player as part of the game system, an agent partly definable by the role the game affords, and as a condition framed by the game's affordances and therefore as an integrated part of the game." While ludo-hermeneutics is not yet a fully elucidated approach to games and meaning, it encourages us to situate the player-interpreter not outside the game looking in but as a participant in an event that is both in need of interpretation and, in a recursive fashion, constituted by interpretation. As Gadamer $(2004,85)$ notes, the encounter with the text "is an encounter with an unfinished event and is itself part of the event.”

In this sense, the present article adopts a ludo-hermeneutic approach. It takes the position that players actively make sense of the game from within the event of play in a pre-linguistic mode of sensation, and that this makes it possible for players to make predicative assertions about what a game means. By focusing on the first of these stages of interpretation-players making sense of a game through their body - the article hopes to develop further the concept of ludo-hermeneutics.

\section{The Body, Meaning and Carnal Hermeneutics}

In his 2007 article on embodiment and Dance Dance Revolution, Behrenshausen (2007) laments the ocularcentrism of much game scholarship, advocating for a conceptualisation of gameplay that attends to senses other than the visual. This would, he convincingly argues, lead to a richer understanding of how games are actually experienced by players. The privileging of sight (and, we might add sound and language) is certainly evident in some game scholarship, but there have been significant efforts, both before and since Behrenshausen's article, to explore the role of the body beyond the eyes and ears in games and gaming (Nørgård 2010b, Nørgård 2010a, Nørgård 2011, 2013a, b, Kirkpatrick 2009, 2011, Flynn 2008, Sudnow 1983).

While this "embodiment" scholarship is valuable in opening up our understanding of games, it has largely bracketed the relationship between the body and hermeneutics. In many of these accounts the body is the site of affect or form, but references to interpretation and understanding are rare. This article addresses this gap in the literature, advancing the argument that the fact of gameplay's embodiment is a matter of interpretation as well as form. 
Richard Kearney (2015) provides an approach to hermeneutics that helps clarify the link I want to make between the body and interpretation in digital games. Kearney's “carnal hermeneutics” lies squarely in the realm of philosophical hermeneutics, drawing as it does on the work of Heidegger, Gadamer, Merleau-Ponty, and Ricœur. It is, then, an attempt to theorise understanding as such rather than how understanding takes place in relation to a particular kind of text. If carnal hermeneutics succeeds in this general aim it should be applicable to the narrower sphere of digital game interpretation. By developing these examples of carnal hermeneutics in the specific case of games, this article seeks also to develop the concept of carnal hermeneutics. Games offer an interesting example of the interaction of text, meaning and body, and so help to extend Kearney's discussions of carnal hermeneutics in new directions. In this section I will outline some of the relevant aspects of carnal hermeneutics and defend its main claims in order to establish that it is indeed a tenable approach to understanding in general. In the following sections I will use three examples to explain its relevance to understanding in the specific context of digital games.

Before summarising the aspects of carnal hermeneutics relevant to the present article, a note on terminology. In his discussions of carnal hermeneutics Kearney draws on a wide range of philosophers who sometimes use key terms such as sense, understanding, meaning, and body in different ways. For example, Kearney begins his essay with Aristotle's discussion of the flesh as the medium of touch in De Anime, but later draws on Merleau-Ponty's very different discussion of the flesh in his working notes for The Visible and the Invisible. For the sake of clarity I will use these terms consistently, though this will occasionally mean that I differ from the terminology of some of the authors discussed.

In the present article "meaning" will be reserved for conscious statements (either stated out loud or internally) that assert what something (a text, an event, a game, an image, an action etc.) is about. "Sense" and "sense-making” will refer to actions that are non-predicative but that make distinctions. In what follows, this capacity to make distinctions in a non-linguistic and non-predicative mode is taken to be a form of interpretation, and so both meaning and sense-making are species of understanding.

The "body" will refer to the "phenomenal body" (Merleau Ponty 2002, 121) through which I act in the world as opposed to the "objective body" that is perceived by others and can be described in relation to objective space. It is the phenomenal body that engages in sense-making. That is, "the body" in this article will refer to the agent of a mode of understanding that makes distinctions in a non-predicative register.

Kearney (2015) sees the great achievement of Husserl and his followers to be the establishment of the body as a site of philosophy. However, he complains that when philosophers like Gadamer and Ricœur turned to hermeneutics in the 1960s they turned away from the body. Carnal hermeneutics is Kearney's attempt to recall the body to the 
sphere of interpretation. He begins by noting the ambiguity of the term "sense," a word that can refer to both meaning (the traditional terrain for hermeneutics) and sensation (the traditional terrain for aesthetics). ${ }^{1}$ To argue that this is more than just etymological coincidence Kearney draws on Aristotle's De Anima (2001), and his discussion of the sense of touch. Writing against philosophical traditions that saw touch as an unmediated and undifferentiating sense, Aristotle claimed that touch has "many differences" (quoted in Kearney 2015, 105). Kearney picks up this point to argue that the medium of touch "gives us space to discern between different kinds of experience-hot and cold, soft and hard, attractive and unattractive” $(2015,102)$. The body can make distinctions, indeed is making distinctions all the time. In touching, we register differences. A similar point is made by $\mathrm{Yi} \mathrm{Fu}$ Tuan when he characterises touch as a sense that is "activated by contrast—alternations of heat and cold, roughness and smoothness, lightness and weight" $(2005,78)$

In making distinctions the body is making sense of the world. This is a form of understanding; a form of interpretation. ${ }^{2}$ It is not, however, the kind of understanding and interpretation that is usually associated with hermeneutics. Traditionally, hermeneutics has concerned itself with interpretation of statements in abstract, symbolic systems, such as language. Interpretation in the body is not predicative, either in terms of mental representations or linguistic statements. The body does not decode or make propositions about texts. But nor does it simply receive raw information. The kind of interpretation that the body engages in is evaluative without being predicative. In this it is close to Heidegger's hermeneutic 'as'-structure:

In dealing with what is environmentally ready-to-hand by interpreting it circumspectively, we "see" it as a table, a door, a carriage or a bridge; but what we have thus interpreted [ausgelegt] need not necessarily be also taken apart [auseinander zu legen] by making an assertion which definitively characterizes it. Any mere pre-predicative seeing of the ready-to-hand is, in itself, something which already understands and interprets (Heidegger 2008, 189)

The body does not make statements about the world, but nor does it simply accept the world's input. It "takes" the world in a certain way: as attractive or repulsive. To

$1 \quad$ Kearney also discusses sense as orientation, however this third term quickly drops from his argument. I do not pursue it here for reasons of space, but Nørgård's (2010a) use of the work of SheetsJohnstone in accounting for the player-avatar relationship would be a useful point of departure for thinking through sense-as-orientation-as-interpretation in digital games.

2 In making the connection between understanding and sensation, Kearney is also clearly bringing together the fields of hermeneutics and aesthetics/perception. While Kearney does not elaborate on this connection, a similar project is attempted by Husserl in his theory of perception, where he discusses "a certain sequence of experiences of the class of sensations, sensuously unified in a peculiar serial pattern, and informed by a certain act-character or 'interpretation', which endows it with an objective sense. This act-character is responsible for the fact than an object, i.e. this inkpot, is perceptually apparent to us.” (Husserl, 1970, 688) 
perceive is to perceive difference in our perceptual field and to evaluate this difference in a pre-linguistic, non-predicative way. If perception were not evaluative in this sense then it would be difficult to account for how babies, who do not become capable of making predicative representations of the world until around the age of two (Bogdan 2009), nonetheless can make sense of their world. They make distinctions and evaluate those distinctions based on sensation; building up an understanding of the world without making predicative assertions about it.

To summarise: carnal hermeneutics claims that the body does not merely receive information but makes sense of the world. This making sense is based on the ability of the body to make distinctions and evaluate these in a non-predicative way. Touch and taste are at the heart of a carnal hermeneutics, being the foundation on which all distinctions we make in the world rest.

Before going on to discuss carnal hermeneutics and the digital game, a note on touch. This article follows Kearney (2015) in focusing on touch as an important mode of carnal hermeneutics. The examples I use focus mainly on touch. However, Kearney envisages carnal hermeneutics as an approach to understanding that goes all the way up to the decoding of highly conventional symbols as well as all the way down to distinctions and classifications made through the body. Carnal hermeneutics, then, is not simply "tactile hermeneutics.”

However, touch does have a privileged place in carnal hermeneutics and so it is necessary to confront from the beginning one of the major challenges of discussing touch: its multisensory nature. Aristotle (2001) identified a single "proper sensible" in each of the senses: sensations that the sense in question is uniquely capable of processingcolour in the case of sight, sound for hearing and so on. Touch is alone in not having a single proper sensible but many possible proper sensibles, such as temperature and pressure. What we experience as touch is also strongly mediated by body position and motion, and so the kinaesthetic and proprioceptive systems are intimately involved in most experiences of touch. This indicates the difficulty of parsing out touch from the other senses. This has been noted within game studies, with Giddings and Kennedy describing digital game play in terms of "plesiovisual kinaesthesia”: "a mediation of motoric sensation through a gesturally determined visuality” (Giddings and Kennedy 2010, 165). I am not attempting to isolate touch here, and so my examples will, while focusing on touch, attempt to carefully describe how different sensations operate collectively to make sense of games.

\section{Carnal Hermeneutics and the Digital game}

Applying carnal hermeneutics to digital games addresses the fundamental ways that players make sense of digital game playing through sensation. It also allows us to discuss the ways players and critics might draw on embodied performances to derive 
meanings, that is, to say what a game is about. In thinking about the carnal hermeneutics of digital games we might better theorise the relationship between bodies and digital texts, and also develop a poetics of digital game production. We might also, by exposing carnal hermeneutics to the specificities of games and gameplay, develop further a philosophical project that is interested in the connection between the body and interpretation in general.

The role of touch in interpretation has been discussed in other media forms, for example in cinema (Sobchack 2004; Marks 2000). Applying this approach to digital games presents a new set of issues. Of course, all media use is embodied (what activity is not?) but digital games make demands of the body that surpass those made by other media forms in both breadth and complexity. Films of different genres generally require the audience to adopt the same bodily configurations. But the digital game player must learn and re-learn often quite complex patterns of movement involving several parts of the body when playing different genres on different platforms. This makes the way the player-body addresses the game an important "variable" in the experience of the game. If interpretation does start in the body then one would expect that the breadth and complexity of body configurations in gameplay make digital games a rich case study for carnal hermeneutics.

Other scholars have discussed the importance of the body in games in a way that brings us close to a carnal hermeneutics. For example, in his discussion of incorporation in digital games Gordon Calleja quotes a player who demonstrates the relationship between touch and vision that can happen in games. Speaking of a memorable experience in World of Warcraft, the player says "I could practically feel the breeze on my face" (Calleja 2007, 257). Of course, this player is using a figure of speech. The player presumably does not experience the breeze in the same way as he would experience a real breeze but what is important here is how the audio-visual array is conceptualised in tactile terms.

In games this synesthetic transformation of audio-visual stimuli into a tactile register is accompanied by patterns of touching and being touched that players are actually involved in when playing digital games-hands on controllers or keyboards most obviously, but also a variety of self-touching and touching of other people and objects. Rikke Toft Nørgård (2011), for example, shows how touch and vision interact in games:

Borderlands and World of Warcraft require players to initiate and navigate the operation of vision through the hand, and thus, by routing the function of vision through manual manipulation the games make the user "see with the hand" (7).

Of course, much of this touching goes on beneath the player's notice and may or may not be directly motivated by or related to the content of the game. Graeme Kirkpatrick (2009), for example, has written about the relationship between onscreen action and the touch of the console controller as the basis of videogame form, arguing that it is 
precisely the repression of the controller in gameplay that gives games their characteristic form.

These are important contributions to the role of touch in games, but they do not primarily set out to address the role of the body in making sense of digital games. In the examples below I will focus on the realm of touch to discuss the foundations of interpretation in the body. In these examples touch is not always repressed, and it often does more than "see"-it also interprets. To say that touch interprets may be seen as giving too much agency to "touch". I could write here "People use touch to interpret". But to do so would too neatly distinguish the body from the self-as-agent-of-interpretation. It is a central claim of my argument that the self that makes predicative statements to do with what a game means is only one form of interpretation, and one that is based on a prior form of non-predicative differentiations at the level of the body. In the first example, I focus on the touch-screen and claim that in games we understand our relationship to the image through an intertwining of self and image, the visible and the tangible. Drawing on carnal hermeneutics I analyse these intertwinings (or chiasms) in one erotic game La Petite Mort (Lovable Hat Cult 2016) to explain how the game represents sex in terms of partnership and generosity rather than domination. In the second example I argue that games from the same genre often have common patterns of touch, and that designers can mine the embodied memory of this generic touch to create meaningful game experiences. In the last example I argue that the meaning of touch is not universal. What touch (or its absence) means is mediated by marketing of digital games, and also more fundamental cultural associations.

\section{Touching the Image}

When playing a game, we understand our relationship to the digital image through a combination of abstract reasoning and non-predicative carnal interpretations. The decisions that designers make when producing a game have implications for both kinds of sense-making. Focusing on carnal interpretations this section will illustrate how the designed elements of one touch-screen game, La Petite Mort encourage players to "take" the image in a certain way: as an autonomous entity that participates in a common experience with the player rather than as an entity subjected to the player's control or mastery. The game encourages this interpretation through its use of touch-screen interface, visual imagery and sound.

In La Petite Mort a heavily pixelated image of a vulva fills the mobile screen; the player's goal is to simulate a climax by touching the image in the right way. The screen registers location and duration of touch as well as speed of movement. Degree of pleasure is signalled by changes in music, sound effects and colour shade. Displeasure is signalled in the same way, and if the player goes too wrong a pop-up message may appear 
with injunctions like "slow down." The game features four different vulvas, each of which respond in different ways to different combinations of touch.

There are many games that have the goal of bringing a virtual woman to orgasm. In many of these games this goal is more to do with the pleasure of playing at controlling a woman's body than participating in a romantic or sexual partnership. But La Petite Mort feels different. I claim that the difference lies partly in how the game sets up structures through which the player understands his or her relationship to the image as one of independent equals, and that this understanding happens through the body in the intertwining of self and image, the visible and the tangible.

Merleau-Ponty (1968) claims that we can only perceive because we are perceptible. One cannot imagine a sentient organism that is not also sensible. In perceiving, in actively sensing the world, we admit ourselves as sensible-as things in the world available for touch, vision, and other senses. In sensing the world we become involved in the "flesh of the world" (248).

Sometimes one becomes keenly aware of this doubleness - of ourselves as sentient and sensible. The following experiment demonstrates this: pick up an object and palpate it in your right hand. Most likely the object itself is central to your attention, and you become less consciously aware of your right hand. To the extent that the right hand appears to your consciousness it does so from the inside, as sentient and interrogatory. Now touch your right hand with your left hand. Most likely, the right hand now has the character not primarily of a sentient but of a sensible thing - a thing in the world; the same sort of thing as the object it holds. What is happening here, Merleau-Ponty argues, is that the right hand is shifting from an interrogating subject touching an object in the world to a thing among things; an object of your body's attention. This experiment only brings to awareness an intertwining (or chiasm, or crossing) between the self and the world that is the constant state of existence.

Even before one touches the right with the left hand, one is already, though to a lesser extent, aware of the object touching us as we touch it. That is, we experience our hand as a tangible thing in the world for the object, even before it becomes a tangible thing in the world for us. Furthermore, even as we observe the right hand palpating the object it takes on the character of a sensible (specifically visible) thing in the world.

Touch is the sense used in this experiment not because it is the only sense through which this intertwining happens but because it is the sense that most easily brings the chiasm into our awareness. To be the sort of being that can see one must also be capable of being seen, but it is easier to remain unaware of our intertwining with the world in vision than in touch, where the world insistently presses against us.

The above experiment shows the chiasm brought into awareness, but we become aware of our bodies in this way in ordinary life too as different activities distribute our 
awareness differently. Similarly, we should expect designed experiences like digital games to modulate this awareness depending on specific design decisions. The way that the senses interact in La Petite Mort intertwines the player and the image in a relationship that neither places the player absolutely outside the image nor collapses the difference between player and image.

Without any reference to the overall theme of the game, my own play-through of the game could be reported like this:

\begin{abstract}
From the menu screen the game prompts me to pick one of four differently coloured options. I select the red option 'Kit' and a pixelated, dark red image fills the screen. There is an ambient electronic soundtrack playing in the background. On the left side of the screen a lighter shade of red appears and then fades. I touch the screen, eliciting the same response. I move my finger around the image and the same effect happens: a lighter shade of red pulses out from the point my finger touches and leaves a trail that rapidly fades to its original. Warm sounds, including one similar to a human voice, are integrated into the music, enriching the soundtrack. I begin to notice that in some areas the trails stay longer and the sounds elicited by my touch are richer. My finger circles an area of the image that has remained "lit up" for a long time and I notice that the areas around this respond more quickly, and stay lighter for longer, creating a large patch of light red on the right side of the image. I move my finger to another part of the screen and notice I can connect up different patches before they disappear, and as I do the soundtrack becomes richer still. I drag my finger quickly down the image; there is a harsh sound as the music resets. The trails disappear. I start again, this time more slowly. Responding to the cues of the colours and sounds my finger finds a steady pace and rhythm. Eventually the entire screen lights up and flashes.
\end{abstract}

This process is not without predicative assertions or the conscious forming and testing of hypotheses. However, this is not all that is happening. At moments, the body is taking a lead on interpretation. This is most clearly seen when something goes wrong. When there is a harsh sound and the colours rapidly fade I immediately know what it means. There is no need for any second-order interpretation: the finger stops what it is doing straight away. This is still, however, an interpretation. We know this because some player-bodies misinterpret this moment. They do not simply fail to understand at an intellectual level what this signifies (that the imagined woman is experiencing displeasure) but they fail to understand at the level of the body how to evaluate this change in the sensory field. Why else would the designers need to supplement these more intuitive cues with the overt text messages that inform the more stubborn players "Slow down" and "I'm sensitive"? Different player-bodies "take" the image in different ways, and do so immediately without the conscious formation of an interpretation. Here is sensation as sense-making.

By avoiding the route of identifying the woman as a particular audio-visual type the game is treading familiar ground in feminist thought and game design (Pozo 2015). However, it is also leaving room for touch to take a leading role in how the player makes sense of the image. In La Petite Mort the eye is usually focussed behind the finger - taking in the differentiations the finger effects on the image. The proximity of finger and eye in this game deepens the alliance between hand and eye that Nørgård (2011) 
describes as "handsight" (after Hansen 2006), while the constant presence of the finger in the visual field forecloses the absolute repression of the hand that Kirkpatrick (2009) identifies in console games. What we're left with is an insistent reminder of our body in both its interrogatory and passive modes.

Passing over the screen, the finger explores the image, creating differences that the eye and ear follow and the player-body makes sense of. But at the same time the finger experiences (is touched by) the resistance of the flat, smooth surface, and the eye catches the finger as a visible thing. This has important implications for how we take the image. The image represents for the player-body a thing in the world but, importantly, so does the player-body. And just as the player-body knows itself to be not just a thing in the world, but also a sentient and searching subject, so too we must grant the image its subjectivity.

Not all touch-screen games make use of this capacity to put us in touch with the image. But those that do show a potential counter-argument to the idea that digital technology represents a deadening of touch (Classen 2005, 404) and an alienation from the world (Robins 1996, Monbiot 2017). Kearney (2014) himself falls into this discoursesurprising given his insistence on touch's always already mediated nature. He sees digital technology as a "move towards excarnation" and one more step in the advance of Barthes' "civilization of the image."

The above analysis of La Petite Mort suggests another way of thinking about the digital image; not as a "move toward excarnation", not as a further removal and withdrawal of humans from the world, but as a means by which the image is incarnatedgranted a place in Merleau-Ponty's "flesh of the world." In touching the image of La Petite Mort we take the other it represents not as an object to be dominated but as a sentient-sensible thing like us. Nancy (quoted in Kearney 2015) writes: "Touching never does away with the interval between us, but turns the interval into an approach.” Attending to carnal hermeneutics allows us to unpack whether this approach has the character of an assault or a caress.

\section{Generic Touch}

Genres of games are often differentiated by generic control schemas. A player familiar with Call of Duty 3 will not need to learn the basic WASD movement pattern when picking up Call of Duty 4. The ability of the body to draw on its past experiences to act appropriately in the present situation is developed by Merleau-Ponty in his discussion of the formation of habit. Using the example of a typist, Merleau-Ponty (2002 166-7) shows that the performance of typing involves "knowledge in the hands" rather than the conscious remembering and recalling of objective distances between fingers and keys or the relative position of keys on the typewriter. 
This has come to be known as "body memory". Thomas Fuchs (2012) distinguishes between explicit recollection, which functions by representing the past, and implicit or body memory, which "re-enacts [the past] through the body’s present performance" (11). One form of implicit memory is "procedural memory", defined as memory involving "patterned sequences of movement, well-practiced habits, skillful handling of instruments, as well as familiarity with patterns of perception” (12). Players who have learned the "patterned sequences of movement" required to play Call of Duty 3, when faced with a game with the same generic control schema will be primed to re-enact these same sequences; their body will expect such a re-enactment to succeed, but is also capable of adapting to differences in the specific patterns required in the present case.

For Merleau-Ponty, the formation of habit through what would later become known as body memory involves meaning and understanding; not the meaning of declarative statements, but rather "the motor grasping of a motor significance" (2002, 165). Here, Merleau-Ponty approaches meaning, understanding and significance (he uses the terms somewhat interchangeably) from a new direction, in which he claims: "To understand is to experience the harmony between what we aim at and what is given” (167). MerleauPonty has been criticised for making too sharp a distinction between conscious meaning-making and bodily understanding (what I am terming "sense-making”). Taking the example of elite athletes, Toner (2017), for example, catalogues the ways in which athletes consciously reflect on their bodily performances in times of crisis (e.g. injuries) and intervals between performance (see also Shusterman 2012). Body memories are not, then, located exclusively in the body. Rather they involve "habitual reflexivity" (Toner 2017)_traffic between non-conscious enactment and deliberate, conscious reflection and adaptation.

It is well known that body memory can also motivate a set of associations at a higher order of meaning. Fuchs (2012) argues that when a body memory is re-enacted in a present situation this can trigger the activation of an "implicit memory core" (19), a process he calls "explication.” The traffic between implicit body memory and a more conscious and active form of remembering and verbalising is also discussed by Michela Summa (2012), who characterises body memory as a "pre-thematic" consciousness of the past that can form the "basic layer for the genesis of higher order meaning formations" (24).

Fuchs, Summa and Merleau-Ponty are most interested in situations when the reenactment of a body memory comes off successfully. However, Toner demonstrates that in moments of crisis the body sometimes fails to understand (in the Merleau-Pontian sense), and this failure often motivates conscious reflection on the failed action. Using this area of philosophical research as a platform, I argue here that the relationship between "pre-thematic consciousness" and "higher order meaning formations" is integral to interpretation in games, and that mining this territory of meaning-making opens up interesting possibilities in the close-reading of digital games. 
To discuss the mis-enactment of body memory and its possible relationship to higher order interpretation, let us take the example of Dear Esther (Pinchbeck 2012), an indie game designed using the same game engine and many of the same art assets as the hugely popular first person shooter Half-Life 2 (Valve 2004). While the look and feel of the two games are very similar there are also many differences. These differences, because of the ground of similarity against which they are experienced, are particularly striking. One of the differences is the effects that specific finger movements have in each game. Digital games involve certain generic hand configurations and finger movements that players can expect to adopt in many different games. For example, if I sit down to play a PC game in which I move a character in three-dimensional spacewhether that is the quite different games of Half-Life 2, Thief, or Skyrim-I will adopt a similar configuration of my hands. I will position my left hand so that my little, ring and middle fingers rest on the "A," "S" and " $D$ " keys respectively and my thumb rests on the space bar. I will position my right hand such that the thumb, right and little fingers hold the mouse in place, the index finger rests on the left button, and the middle finger on the right button. Different players may adopt different generic configurations, but whatever that configuration is, it will generally be adopted across different games and even, within limits, across game genres. Sometimes I will feel the need to make some slight adjustments to this configuration, but there is nonetheless a fairly standard generic template that I remember and apply without conscious effort as I move between games. Nørgård describes this kind of encoding as an "in-body experience” (2011,9) and shows the implication of this to be that the relationship with the game is "stored and recalled” in the player's body. However, I draw on Toner's (2017) critique of MerleauPonty to claim that these memories are not only recalled in the body, but can also become available for conscious reflection, especially though not exclusively in times of "crisis" when the re-enactment of the body memory fails to "understand" the present situation.

The sense-making that relies on the body memory of these manual configurations becomes available as meaning when the player consciously links the experience of performing these configurations (either successfully or unsuccessfully) to other aspects of the game in a predicative statement on what the game is about. Using Dear Esther as an example it is possible to trace this trajectory between a mis-enacted gesture, sensemaking and meaning.

Gestures learned and regularly deployed in Half-Life 2 include-for me, but also, I imagine for many other players-moving the little finger of the left hand from above the "A" key to the SHIFT key, the pressing of which makes the player-character sprint; pressing the SPACE bar with the left thumb to make the player-character jump; or clicking the mouse with the right index finger to use a weapon. In Dear Esther the generic address is similar to the one I have described above for three-dimensional games. But 
these actions - pressing the SHIFT key, the SPACE bar and the right mouse button-so familiar to the player of Half-Life 2, are drained of these functions. In Dear Esther, pressing the SHIFT key does nothing. At the level of the body, and taking MerleauPonty's definition of understanding as harmony between intention and performance, my body understands the SHIFT key as sprint in Half-Life 2 but fails to understand it, at least initially, in Dear Esther. But this draining of function-and consequent misunderstanding-is itself significant when seen in relation to the game's overarching themes (see Leino 2011 and 2013 for discussion of the significance of absence of game tropes in art games) .

While different players no doubt experience Dear Esther in different ways, I would argue that for players familiar with Half-Life 2 these "empty” keys are not really empty at all. Other keys in Dear Esther also lack a specific function, for example, CAPS LOCK or "M." But this lack is relatively simple because it is not different from the gestural configuration of Half-Life 2 that is stored in the body memory of players of that game. The importance of difference to meaning is well-known in semiotic theory, which sees language as a system of differences (Saussure 2011). In semiotic analysis the meaning of a word in a sentence is understood through its difference from the surrounding words in the sentence (the syntagm) and its difference from absent alternatives in the linguistic system (the paradigm). Drawing on this method one might posit a paradigmatic analysis of sense-making in Dear Esther's control scheme. Such an analysis would require an identification of the broad genre of which Dear Esther is a part. For Source Engine games, there are a number of conventional effects of, for example, the SHIFT key. Dear Esther has substituted the most conventional effect of this ("sprint") out and replaced it with no function. Because games ask us to situate them within a generic template (this is how I know how to address Dear Esther in the first place) the absence of a function in the SHIFT key (and in the SPACE bar and the right mouse button) are not simply irrelevant to the playing of the game (as is, for example, the absence of function in the "M" key). The absence of function in the SHIFT is registered at the level of the body through its difference from SHIFT's plenitude in Half-Life 2, the model for this type of game. Pressing the SHIFT key leads to an acknowledgement of something absent that passes through the body without necessarily a conscious thought.

For Giddings and Kennedy, control in a digital game is often "below attention, beneath consciousness" (2010, 176). Similarly, Kearney argues that the interpretations of the body happen without the conscious decoding that we generally associate with interpretation. But it is important to modify these claims. In spite of the fact that carnal hermeneutics often happens beneath consciousness, the distinctions made by the body that resonate in what film-maker Jan Švankmajer (2014) calls the "tactile imagination" are integral to the meaning of games. As Kearney notes, carnal hermeneutics goes all the way up and all the way down. The tactile imagination, built up through the sense- 
making of sensation is the resource from which predicative interpretations of what the game is "about" are derived.

Absence is integral to Dear Esther. There is absence in its isolated setting, in its restrained exposition, in its haunting music. And all of this makes sense in terms of the story of loss, grief and guilt related through the voiceover. But this sense of absence is first established — at least potentially — in the sense of loss of the empty SHIFT key. The game begins with the character in the water facing an island. The player with generic experience of the first person shooter and of Half-Life 2 in particular will intuitively know that the island is where the game is going to take place, that getting to the island is the first task to be completed, and that this should be done as quickly as possible, as very little will happen before getting there. These expectations prime the experienced player to reach for the shift key to complete this task. But when the SHIFT key is pressed, the character does not sprint. The game equipment does not work, or at least not in the expected way.

Much of the setup of Dear Esther primes the player to anticipate an experience similar to Source-based FPS games, and this includes the control schema. In attempting to enact the body memory associated with this control schema the player's body is disappointed. Fuchs does briefly mention the situation where the enactment of a particular procedural memory is anticipated but fails to materialise. He says the experience of this is one of "surprise" $(2012,12)$ but does not elaborate on this experience. But others have noted similar experiences. Martin Heidegger (2008) comments on the experience of reaching for equipment to get a job done and finding it absent. When that happens, the equipment we are left with is "obtrusive". It is not what we need, and the presence of this inappropriate stuff is obnoxious to us. By playing on the body memory of the player familiar with Half-Life 2, Dear Esther fills the emptiness of the SHIFT key with the meaning of absence, and establishes a connection between deficiency within the player's repertoire of touches and the character's experience of absence as grief. In other words, the sense-making at the level of sensation (the immediate and unarticulated feeling of obtrusiveness experienced at the level of the body) can be put to use in a more traditional reading of the game involving predicative statements (a reading that links absence experienced by the body with absence communicated through the game's story and atmosphere). In focusing on the relationship between memory, enactment and meaning, the foregoing analysis suggests a methodology for close-reading in digital games, but it also offers a case study that lends concreteness to the theory outlined by some of the philosophers and theorists in this section. In particular, the foregoing analysis adumbrates the contours of the "surprise" that Fuchs (2012) mentions in relation to a disappointed procedural memory. 


\section{Marketing Touch}

While the smart-phone's touch-screen was changing the role of touch in mobile gaming, another development was changing the role of touch in console gaming in a very different way-gestural interfaces. All three consoles launched in 2005/2006-Nintendo's Wii, Sony's PlayStation 3 and Microsoft's Xbox 360-employed gestural interfaces in one way or another. While the Wii and the PlayStation Move required players to hold controllers for their gestures to be captured by the console, the Microsoft Kinect severed the traditional tactile connection between player's hand and console. If the touch-screen put players in direct touch with the image, the Kinect did the opposite. While the Kinect-like the Wii and the Move-was sold through a discourse of the body, this was a body characterised entirely by the kinaesthetic and proprioceptive. By diminishing the tactile element, Kinect creates a different relationship by removing the insistent reminder of the chiasm that direct contact with objects in the world provides us. The most immediate effect of this in terms of gameplay is that the player does not experience resistance to her moves in the heft of a controller and so gestures feel lighter. Furthermore, force feedback - first introduced to game consoles via the Nintendo 64's Rumble Pak-is not available. But this separation has deeper consequences in terms of the relationship between player and computer, a difference that is highlighted if we compare the marketing for different console controllers.

Controllers are always, as one would expect, described by their manufacturers in terms of control, but this control is framed differently for the wireless controllers of the Xbox One (Microsoft 2016a) and the PlayStation 4 (Sony 2016a), the tactile gestural controllers of PlayStation Move (Sony 2016b) and the Nintendo Wii-U (Nintendo 2016) and the touchless controller of Microsoft's Kinect 2 (Microsoft 2016b). Descriptions of the wireless controllers for Sony's PlayStation 4 and Microsoft's Xbox One emphasise precision, accuracy, speed, and comfort. The copy uses terms like "intensity" and "feel," describing how the controller immerses the player in the action of the gameworld through force feedback. The PlayStation Move also draws on a discourse of "feeling" and the immediate connection between the player and the gameworld. Game experiences, it claims, are “delivered directly to the palm of your hand.” The copy for the Wii-U's controller, which is a tablet that serves both as a controller and a second screen, emphasises how this controller connects players together, but also creates a "relationship" between the player and the television/console. What is striking in this advertising is how the game console is described almost as another member of the family - the "we" of the Wii-U includes the machine itself. The tactile connection between player and machine via the tablet controller is an essential part of the forging of this almost familial connection.

The Kinect 2's ad copy is markedly different from this. If the wireless controllers are about precision, the PlayStation Move is about feel, and the Wii-U is about a familial 
relationship with technology, the Kinect 2 is about power. The keyword in Kinect 2's copy is "command," for example in lines such as "Command your Xbox and TV with your voice" or "Take command of your entertainment." The command has a long history in human-computer interaction, with its roots in the military's role in the development of computing technology. This explains why Kinect 2 describes the instructions that players input through words and gestures as commands. Kinect 2's ads play on this term, and in doing so frame the relationship between player and Xbox One as one of human as master and computer as subordinate. The ease with which the player can make the Kinect 2 do its bidding is seen in the phrase "Navigate your console without lifting a finger.” Perhaps the most evident characterisation of the player-computer relationship as one of domination and subordination is the Kinect's main slogan: "You are the controller." The slogan is not a technical description of the Kinect, but rather a rhetorical separation of the player from the manual labour of pushing buttons. The player becomes a supervisor, manager, or general, issuing commands without getting his hands dirty.

How different this is from the framing of the Wii-U. Rather than being another member of the family, the Kinect 2 is a subordinate. One is tempted to draw on Dorinne Kondo's (2005) discussion of craft and mass production in Japan to make sense of this difference. Kondo finds that craftsmen in Japan have a close relationship with the materials they work with, in which the materials they use are viewed as collaborators rather than mere objects or subordinates. While this is perhaps unsurprising in craft, Kondo finds the same kind of relationship of equals among machine-workers and their machines in settings of industrial mass-production. She explains this in terms of the Shinto belief that all objects have kami and that this creates a cultural context in Japan more likely to afford technologies of production (and we might tentatively say, entertainment too) a certain modicum of respect and dignity.

Whatever its cultural explanation, this difference between the Wii-U and the Kinect 2 , articulated in language in the ad copy for the different controllers, is something that a carnal hermeneutics already intuits in playing with these controllers. That it is not raised to language in ordinary play does not mean that it is "pre-interpretative" but that it takes a particular form of bodily interpretation.

In doing away with the manual labour of traditional control set-ups the Kinect 2 also does away with touch's unique ability to aestheticize the difference between subject and object of touch. Again one is reminded of Nancy's description of touch as initiating an intersubjective approach without collapsing difference. The flesh, at the interface between self and stranger risks the other and so opens to the other. In bypassing the touch of the flesh the Kinect 2 impoverishes digital gameplay in one of its most interesting areas - in how it puts us in touch with digital technology. 


\section{Conclusion}

In this article I have relied on my own experiences playing computer games. However, carnal hermeneutics suggests a number of different methodologies that could expand how we think of "close-reading” in games. In this, Nørgård (2013b) has made important contributions in her methodology of "gameplay corporeality." Comparing how different players use their bodies to make sense of games and investigating whether different modes of addressing games give rise to different patterns of sense-making would be a potentially fruitful area of empirical research.

This article has attempted to extend ludo-hermeneutics by looking at sense-making through sensation. By reflecting on my own playing of computer games I have argued that this form of sense-making takes place alongside conscious attempts to decode the game as "text" through predicative statements to do with the game's meaning. Interpretations in each of these modes inform each other. We can say what a game is about because we have already made sense of it as a visible, audible, tangible/touching thing. Equally, how we touch and are touched by the game, how we see it, how we hear it, is influenced by what we think the game is about. Carnal hermeneutics is not an attempt to replace other theories of meaning in games but to supplement them with a theory of how understanding happens through the body.

\section{Games}

Pinchbeck, Dan. 2012. Dear Esther. Windows.

Lovable Hat Cult. 2016. La Petite Mort. Mobile.

Valve. 2004. Half-Life 2. Windows.

\section{References}

Aarseth, Espen. (2003). Playing Research: Methodological Approaches to Game Analysis. Australia DAC, Melbourne.

Aarseth, Espen. (2013). Ludology. In The Routledge Companion to Video Game Studies, edited by Mark J.P. Wolf and Bernard Perron. Abingdon: Routledge.

Aristotle. 2001. On the Soul: Infomotions Inc.

Arjoranta, Jonne. (2011). Do We Need Real-Time Hermeneutics? Structures of Meaning in Games. Proceedings of DiGRA 2011 Conference: Think Design Play.

Behrenshausen, Bryan G. (2007). Toward a (Kin)Aesthetic of Video Gaming: The Case of Dance Dance Revolution. Games and Culture 2 (4):335-354.

https://doi.org/10.1177/1555412007310810

Bogdan, Radu J. (2009). Predicative Minds. Cambridge, MA and London: MIT Press

Calleja, Gordon. (2007). Digital Game Involvement. A Conceptual Model. Games and Culture 2 (3):236-260. https://doi.org/10.1177/1555412007306206.

Clarkson, Michael. (2009). Critical Compilation. Bioshock. Critical Distance, accessed 23rd of March. http://www.critical-distance.com/2009/06/17/bioshock/.

Classen, Constance. (2005). Touch and Technology. In The Book of Touch, edited by Constance Classen, 401-406. Oxford and New York: Berg.

Flynn, Bernadette. (2008). The Navigator's Experience: An Examination of the Spatial in Computer Games. In The Pleasures of Computer Gaming: Essays on Cultural History, Theory and 
Aesthetics, edited by Melanie Swallwell and Jason Wilson, 118-146. Jefferson, NC and London: McFarland \& Company.

Fuchs, Thomas. (2012). The Phenomenology of Body Memory. In Body Memory, Metaphor and Movement, edited by Sabine C. Koch, Thomas Fuchs, Michela Summa and Cornelia Müller, 922. Amsterdam and Philadelphia: John Benjamins Publishing Company.

Gadamer, Hans-Georg. (2004). Truth and Method. Translated by Joel Weinsheimer and Donald G. Marshall. London and New York: Continuum. Original edition, 1960.

Giddings, Seth, and Helen Kennedy. (2010). 'Incremental Speed Increases Excitement': Bodies, Space, Movement and Televisual Change. Television and New Media 11 (3):163-179. http://dx.doi.org/10.1177/1527476409357592

Hansen, Mark B.N. (2006). Bodies in Code: Interfaces with Digital Media. New York: Routledge.

Heidegger, Martin. (2008). Being and Time. Translated by John Macquarrie and Edward Robinson. New York: Harper \& Row. Original edition, 1927.

Husserl, Edmund. (1970). Logical Investigations. Translated by J.N. Findlay. New York: Humanities Press. Original edition, 1900/1901.

Karhulahti, Veli-Matti. (2015). Hermeneutics and Ludocriticism. Journal of Games Criticism 2 (1):1-23.

Kearney, Richard. (2014). Losing Our Touch. The Stone, August 30th 2014.

Kearney, Richard. (2015). What is Carnal Hermeneutics? New Literary History 46 (1):99-124. https://doi.org/10.1353/nlh.2015.0009

Kirkpatrick, Graeme. (2009). Controller, hand, screen. Aesthetic Form in the Computer Game. Games and Culture 4 (2):127-143. https://doi.org/10.1177/1555412008325484

Kirkpatrick, Graeme. (2011). Aesthetic Theory and the Video Game. Manchester: Manchester University Press.

Kondo, Dorinne. (2005). Polishing Your Heart: Artisans and Machines in Japan. In The Book of Touch, edited by Constance Classen, 409-411. Oxford and New York: Berg.

Leino, Olli Tapio. 2011. Re-Conceptualising the Play-Element in Electronic Art. In Proceedings of The $17^{\text {th }}$ International Symposium on Electronic Art, Istanbul, Turkey. http://isea2011.sabanciuniv.edu/paper/re-conceptualising-play-element-electronic-art.

Leino, Olli Tapio. 2013. Playability and Its Absence-A Post-Ludological Critique. In Proceedings of DiGRA 2013: DeFragging Game Studies. Digital Games Research Association DiGRA, Atlanta, GA. http://lmc.gatech.edu/ cpearce3/DiGRA13/papers/paper_263.pdf.

Marks, L.U. (2000). The Skin of the Film: Intercultural Cinema, Embodiment, and the Senses. Durham and London: Duke University Press.

Merleau-Ponty, Maurice. (1968). The Visible and the Invisible. Followed by working notes. Translated by Alphonso Lingis. Edited by Claude Lefort. Evanston: Northwestern University Press. Original edition, 1964.

Merleau-Ponty, Maurice. (2002). Phenomenology of Perception. Translated by Colin Smith. London and New York: Routledge. Original edition, 1945.

Monbiot, George. (2017). Our Greatest Peril? Screening Ourselves off from Reality. The Guardian, 28/2/2017. Accessed 28/3/2017. https://www.theguardian.com/commentisfree/2017/feb/28/greatest-peril-screening-reality-4chanpewdiepie-nothing-matters-fascism.

Nintendo. (2016). A Completely New Console with a Brand New Controller. Accessed May 15, 2016. https://www.nintendo.co.uk/Wii-U/Hardware-Features/Hardware-Features-660145.html.

Nørgård, Rikke Toft. (2010a). The Body under the Mask : Unveiling the Corporeal Practice of Gamers. Under the Mask 2010: Perspectives on the Gamer, Luton, UK.

Nørgård, Rikke Toft . (2010b). Stillborn Gamers? Writing a Birth Certificate for Corporeality and Locomotion in Game Research. Nordic DiGRA, Experiencing Games: Games, Play, and Players, Stockholm, Sweden.

Nørgård, Rikke Toft . (2011). The Joy of Doing : The Corporeal Connection in Player-Avatar Identity. Philosophy of Computer Games, Athens, Greece.

Nørgård, Rikke Toft . (2013a). Corporeal-Locomotive Media: Experiencing First Person Being and First-Person Doing in Onscreen-Offscreen Gameworlds. Nordmedia 2013: Defending Democracy, Oslo, Norway. 
Nørgård, Rikke Toft . (2013b). Endeavors to Represent the Non-Representational : Researching Corporeal-Locomotive Media. Nordmedia 2013: Defending Democracy, Oslo, Norway.

Pozo, Diana. (2015). Countergaming's Porn Parodies, Hard Core and Soft. In Rated M for mature. Sex and Sexuality in Videogames, edited by Matthew Wysocki and Evan W. Lauteria, 133-146. London and New York: Bloomsbury Academic.

Robins, Kevin. (1996). Into the Image. Culture and Politics in the Field of Vision. London and New York: Routledge.

Saussure, F. (2011) Course in General Linguistics. Translated by Wade Baskin. Edited by Perry Meisel and Haun Saussy. New York: Columbia University Press. Original edition, 1916.

Shusterman R (2012) Thinking Through the Body: Essays in Somaesthetics. Cambridge: Cambridge University Press.

Sobchack, V. (2004). Carnal thoughts. Embodiment and Moving Image Culture. Berkeley and Los Angeles: University of California Press.

Sony. (2016a). DualShock 4 Wireless Controller. Accessed May 15, 2016. https://www.playstation.com/en-us/explore/accessories/dualshock-4-wireless-controller-ps4/.

Sony. (2016b). PlayStation ${ }^{\circledR}$ Move. Accessed May 15, 2016. https://www.playstation.com/enus/explore/accessories/playstation-move/.

Sudnow, David. (1983). Pilgrim in the Microworld: Warner Books.

Summa, Michela. (2012). Body Memory and the Genesis of Meaning. In Body Memory, Metaphor and Movement, edited by Sabine C. Koch, Thomas Fuchs, Michela Summa and Cornelia Müller, 23-43. Amsterdam and Philadelphia: John Benjamins Publishing Company.

Švankmajer, Jan. (2014). Touching and Imagining: An Introduction to Tactile Art Translated by Stanley Dalby. London, UK and New York, NY: I.B. Tauris.

Toner, John. (2017). Habitual Reflexivity and Skilled Action. Body \& Society. https://doi.org/10.1177/1357034X17736371

Tuan, Yi Fu. (2005). The Pleasures of Touch. In The Book of Touch edited by Constance Classen, 74-79. Oxford and New York: Berg.

Microsoft. 2016a. Xbox One Wireless Controller. Accessed May 15, 2016. http://www.xbox.com/enUS/xbox-one/accessories/kinect-for-xbox-one.

Microsoft. 2016b. Kinect for Xbox One. Accessed May 15, 2016. http://www.xbox.com/enUS/xbox-one/accessories/kinect-for-xbox-one. 